\title{
EFEITO DO CLORETO DE SÓDIO NA PRODUÇÃO DE PROTEÍNAS (Saccharomyces cerevisiae) EM FERMENTAÇÃO SEMI-SÓLIDA ${ }^{1}$
}

\author{
Ana Maria RODRIGUES ${ }^{2}$, \\ Ernani S. SANT'ANNA2,*
}

\begin{abstract}
RESUMO
Estudou-se o efeito do cloreto de sódio sobre a produção de biomassa e proteínas extracelulares totais, durante o cultivo de Saccharomyces cerevisiae. A levedura foi desenvonvida em fermentador de leito fluidizado, com vazão de ar de $70 \mathrm{~L} / \mathrm{min}$, temperatura de $33^{\circ} \mathrm{C}$, e umidade relativa de $99-100 \%$. Foi utilizado substrato semi-sólido de batatas, previamente hidrolizado, acrescido de cloreto de sódio $0,6 \mathrm{M}$. O crescimento celular foi monitorado por densidade óptica à $595 \mathrm{~nm}$. Observou-se, como resultado, que a adição de cloreto de sódio 0,6M induziu um aumento de $36,86 \%$ na produção de proteínas extracelulares totais, mas inibiu o crescimento celular em $27,62 \%$ quando os meios com e sem cloreto de sódio foram testados. A produção máxima de biomassa, tanto para os experimentos com adição de cloreto de sódio quanto para o sem adição, ocorreu no período de 7 a 9 horas de fermentacão, enquanto que a produção de proteínas extracelulares totais, independentemente da adição do sal, ocorreu durante o período de 9 a 12 horas de fermentação. As velocidades específicas máximas de crescimento foram de $0,350 / \mathrm{h}$ para os experimentos com sal, e de $0,339 / \mathrm{h}$ para aqueles sem a adição do sal. A combinação de alta vazão de ar e a presença de cloreto de sódio $0,6 \mathrm{M}$ na fermentação parece não ter tido efeito sobre a duração da fase lag na curva de crescimento celular de Saccharomyces cerevisiae.
\end{abstract}

Palavras-chave: Fermentação em leito fluidizado, Saccharomyces cerevisiae, proteínas extracelular.

\section{SUMMARY}

EFFECT OF SODIUM CHLORIDE ON PROTEIN PRODUCTION (Saccharomyces cerevisae) BY SEMI-SOLID FERMENTATION. The effect of sodium chloride on the cell's growth and total extracellular protein production during fermentation of Saccharomyces cerevisiae in an air-fluidized bed fermentation, with a $70 \mathrm{~L} / \mathrm{min}$ air flow at $33^{\circ} \mathrm{C}$ and $99-100 \%$ relative unidity was studied. A semi-solid potato substrate (previously hydrolized) with $0.6 \mathrm{M}$ sodium chloride was used. Cell's growth was monitored by optical density at $595 \mathrm{~nm}$. Results showed that the addition of $0.6 \mathrm{M}$ sodium chloride enhanced total extracellular protein level $(36.86 \%)$. On the other hand, the addition of sodium chloride inhibited cell growth (27.62\%), when mediums with and without sodium chloride were tested. The maximum yield of biomass was achieved at the 7 - 9th hour fermentation for experiments either with or without addition of sodium chloride, while maximum yield of total extracellular proteins was achieved at the 9 - 12th hour fermentation, in all runs. The maximum specific cell's growth rate averaged $0.350 / \mathrm{h}$ for the experiments where salt was added and $0.339 / \mathrm{h}$ for those without salt. Finally, it seemed that the length of the lag phase had not been affected by the combination

$\overline{{ }^{1} \text { Recebido para publicação em 18/07/00. Aceito para publicação }}$ em 06/04/01.

${ }^{2}$ Universidade Federal de Santa Catarina - Depto. de Ciência e Tecnologia de Alimentos. Rod. Admar Gonzaga, 1.346. Florianópolis, SC.E-mail:ernanis@cca.ufsc.br

${ }^{*}$ A quem a correspondência deve ser enviada. of high air flow rate and the presence of $0.6 \mathrm{M}$ sodium chloride in the yeast growth curve in this air-fluidized bed fermentation of Saccharomyces cerevisae.

Keywords: Air-fluidized bed fermentation, Saccharomyces cerevisae, extracellular protein.

\section{1 - INTRODUÇÃO}

Proteínas unicelulares, principalmente para uso em ração animal ainda continuam despertando interesse por razões amplamente levantadas e discutidas por inúmeros pesquisadores $[8,10,17]$. Convencionalmente estas proteínas são obtidas por fermentação submersa, mas ultimamente tem-se voltado a atenção para as culturas em estado sólido e semi-sólido [25,3].

Dentre os microrganismos, as leveduras têm se destacado como uma excelente fonte de proteínas, não apenas pela sua capacidade de sintetizá-las e a outros compostos, mas também por suas características não patogênicas, podendo ser usadas tanto como alimento humano quanto como ração [13].

Quando as leveduras são usadas na ração animal, não há necessidade de remoção dos ácidos nucléicos $[20,5]$. Com exceção dos primatas e do homem, onde o ácido úrico é o produto final do metabolismo e é excretado, os outros mamíferos e demais animais terrestres, possuem uricase, que degrada o ácido úrico em alantonina e uréia. Nas aves, o principal produto de degradação não é a uréia e sim o ácido úrico, porque nestes animais a uréia não é sintetizada a partir da amonia [7].

A ação inibidora de sais inorgânicos em fermentações foi relatada pela primeira vez por TAJIMA, YOSHIZUMI, TERASHIMA [21] e UMEMOTO, IRIE, IMAI [24]. O cloreto de sódio, além de inibidor de microrganismos e de metabólitos tóxicos influi sensivelmente no metabolismo de muitos microrganismos, particularmente no conteúdo protéico [24].

NORKRANS [16] relatou que $4 \%$ de sal reduz o crescimento de Saccharomyces cerevisae em torno de 10-15\%, quando comparados com o controle (sem sal) e que $8 \%$ de $\mathrm{NaCl}$ reduz a biomassa em $90 \%$. RICHMOND [19], estudando o efeito de altas concentrações de sal na produção de L-lisina, observou que o $\mathrm{Nacl}$ a $1 \%$ inibe o crescimento de Pediococcus acidilactici. MALANEY, TANNER, RODRIGUES [12] constataram que $40 \mathrm{~g}$ de $\mathrm{NaCl}$ por litro reduz a produção de células de Saccharomyces cerevisiae em substrato semi-sólido.

A redução do crescimento celular pode ser explicado pela presença de $\mathrm{NaCl}$ no meio, que reduz a atividade de água causando um aumento na perda de água 
das células microbianas para o meio, promovendo plasmólise nas células, aumentando bruscamente a concentração de aminoácidos [7].

Por outro lado, TEMPEST, MEERS, BROWN [23] registraram que quando o conteúdo de $\mathrm{NaCl}$ no meio de crescimento de Aspergillus aerogenes foi aumentado de $0,1 \%$ para $2 \%$ e então para $4 \%(0,68 \mathrm{M})$, a produção de ácido glutâmico intracelular aumentou sucessivamente de 8 para 32 e então para $134 \mathrm{mM} / \mathrm{L}$. Estes mesmos autores constataram ainda que a adição de $2 \%$ de $\mathrm{NaCl}$ promove um aumento significativo no conteúdo de aminoácidos em Bacillus subtilis variedade níger.

MALANEY,TANNER [11] verificaram que o $\mathrm{NaCl}$ afeta profundamente a concentração dos aminoácidos do ciclo da uréia, implicando numa ligação entre troca de pressão osmótica e balanço de nitrogênio/uréia nas células de Saccharomyces cerevisiae em fermentação aerada da glicose.

O cloreto de sódio exógeno tende a aumentar a quantidade de aminoácidos extracelulares em relação aos aminoácidos intracelulares em Saccharomyces cerevisiae, utilizando meio de cultura líquido, aerado. Segundo estes autores, o sal provoca um stress na membrana celular do microrganismo pela alteração da pressão osmótica, provocando um vazamento dos aminoácidos intracelulares [6]. Ademais, a adição do sal parece provocar uma maior permeabilidade da membrana plasmática, permitindo, desta maneira, uma passagem dos aminoácidos intracelulares para o meio externo [12].

A diferença básica entre as fermentações em estado sólido e cultura submersa está no conteúdo de água do substrato. Enquanto na cultura em estado sólido, o conteúdo de água do substrato varia entre $40 \%$ e $80 \%$, na cultura submersa típica, o conteúdo de água é superior a 95\% [8]. Na cultura líquida, o substrato, na forma de pequenas partículas, é suspenso ou dissolvido no líquido, geralmente água, juntamente com o microrganismo ativado [21].

A escolha do processo fermentativo em estado sólido deve se basear nas considerações sobre as vantagens e desvantagens do método quando comparadas com a cultura submersa [17]. Os maiores problemas da fermentação em estado sólido consistem no monitoramento e controle de $\mathrm{pH}$, temperatura, conteúdo de água, agitação e homogeneização durante todo o processo de fermentação [9]. Para eliminar estes problemas de monitoramento e controle do processo, foi proposto o crescimento microbiano em câmara fluidizada, onde o substrato é insuflado com ar esterilizado [21].

Uma câmara fluidizada consiste num sistema típico de água no ar, ao invés ar na água, como fermentação convencional. A câmara fluidizada emprega altas vazões de ar para efetivamente aerar o substrato e simultaneamente misturar de maneira mais eficiente 0 mosto, sem empregar a agitação mecânica [12]. A produção de single cell protein em câmaras fluidizadas é atrativa, não só pela possibilidade de controle mencionada acima, mas também, em função da possibilidade de eliminação da necessidade de resfriamento, bem como centrifugação e filtração da suspensão microbiana [15].

O objetivo do presente trabalho foi estudar a produção de proteínas extracelulares totais a partir de Saccharomyces cerevisae, utilizando uma câmara fluidizada com alta vazão de ar, em substrato semisólido na presença e ausência de cloreto de sódio.

\section{2 - MATERIAL E MÉTODOS}

\section{1 - Microrganismo}

O microrganismo utilizado foi Saccharomyces cerevisiae, na forma de fermento de pão, granulado seco - (Fleishmann). A cada experimento foi utilizado um novo pacote de fermento, utilizando $3,6 \mathrm{mg}$ de fermento de pão granulado seco por grama de substrato.

\section{2 - Meio de cultura (substrato)}

Como substrato foram utilizadas batatas (Solanum tuberosum), adquiridas no mercado local, observando a mesma procedência. Aproximadamente $400 \mathrm{~g}$ de batatas descascadas e lavadas foram cozidas e esterilizadas em autoclave a $121^{\circ} \mathrm{C}$, durante $15 \mathrm{~min}$., e então trituradas em liqüidificador. À pasta assim obtida foi adicionado meio de cultura esterilizado contendo $\alpha$-amilase (fúngica) dissolvida. A quantidade de enzima usada na mistura foi de $0,51 \mathrm{mg} / \mathrm{g}$ de batata úmida. Esta mistura de batata com $\alpha$-amilase ficou em repouso à $25^{\circ} \mathrm{C}$ por 12 a 14 horas, para permitir a conversão do amido da batata em açúcares.

Parte dessa pasta de batatas, tratada com $\alpha$-amilase e contendo o meio de cultura de MAXON e JONHSON [14], foi utilizada para preparar a curva de calibração, como padrão (branco), utilizada na determinação da concentração celular e das proteínas extracelulares totais. O restante da pasta foi pesado e misturado com a suspensão de meio de cultura restante e o inóculo de Saccharomyces cerevisiae (3,6 $\mathrm{mg} / \mathrm{g}$ de batata úmida) para então ser colocado no fermentador sobre o prato de Teflon ( Figura 1). A massa inicial do substrato (mistura de batatas cozidas, enzima, e meio de cultura) foi de $\pm 10 \mathrm{~g}$. O pH inicial foi igual a $5 \mathrm{em}$ todos os experimentos e não foi monitorado durante a fermentação $[9,12,22]$.

Os experimentos com cloreto de sódio obedeceram aos mesmos procedimentos acima mencionados, acrescidos de $0,6 \mathrm{M}$ de $\mathrm{NaCl}$. O sal foi adicionado à pasta de batatas tratada com a enzima ( $\alpha$-amilase) momentos antes de inocular o microrganismo. Foi coletada uma alíquota desta pasta, contendo o cloreto de sódio para execução da curva de calibração e amostra padrão (branco), para determinação da concentração celular e proteínas extracelulares totais. Pesou-se, então, $300 \pm 10 \mathrm{~g}$ desta pasta e a ela foi misturada a suspensão do microrganismo na quantidade previamente descrita. 


\section{3 - Meio de cultura Suplementar}

Foi utilizado o meio de cultura sintético de MAXON e JONHSON concentrado [14], sem glicose, como suplemento de substrato de batatas. O meio apresenta a seguinte composição: $\left(\mathrm{NH}_{4}\right) \mathrm{H}_{2} \mathrm{PO}_{4} 10,0 \%$; $\mathrm{KH}_{2} \mathrm{PO}_{4} 4,0 \%$; citrato de sódio $1,0 \%$ diluídos em água destilada formando a solução $\mathrm{A}$; $\mathrm{MgSO}_{4} .7 \mathrm{H}_{2} \mathrm{O} 1,5 \%$; $\mathrm{ZnSO}_{4} .7 \mathrm{H}_{2} \mathrm{O}$ $0,035 \% ; \mathrm{FeSO}_{4}\left(\mathrm{NH}_{4}\right) \mathrm{SO}_{4} \cdot 6 \mathrm{H}_{2} \mathrm{O} 105 \mathrm{mg} / \mathrm{L} ; \mathrm{CuSO}_{4} \cdot \mathrm{H}_{2} \mathrm{O}$ $9,6 \mathrm{mg} / \mathrm{L}$ diluídos em água formando a solução $\mathrm{B}$. Biotina 2,0mg/L; Cloridrato de piridoxina 120mg/L; Pantotenato de cálcio $50 \mathrm{mg} / \mathrm{L}$; Meso-inositol 1,0g/L diluídos em água formando a solução $C$. As três soluções são misturadas em partes iguais momentos antes do uso. Este meio foi usado em uma concentração 3 vezes superior à concentração original, objetivando limitar o conteúdo de água inicial do substrato sólido em torno de $80 \%$. 0 meio de cultura foi esterilizado a $121^{\circ} \mathrm{C}$ durante 15 minutos antes de sua adição ao substrato sólido. A quantidade de meio suplementar utilizada foi de $0,15 \mathrm{~mL} /$ $\mathrm{g}$ de batata. Aproximadamente $60 \%$ do total do meio de cultura foi utilizado para dissolver a enzima ( $\alpha$-amilase), de origem fúngica - marca Sigma. A solução resultante foi misturada ao substrato de batatas. O restante do meio de cultura (40\%) foi usado para reativar as células do inóculo. Esta mistura também foi adicionada no substrato de batatas.

\section{4 - Fermentador (câmara fluidizada)}

O diagrama da câmara fluidizada está apresentado na Figura 1. Todo o sistema foi esterilizado por vapor, antes de iniciar a fermentação. A esterilização do ar foi obtida por filtração em lã de vidro estéril. Para uma apropriada umidificação, o ar foi forçado através de uma coluna de vidro contendo água, preenchida com cilindros de cerâmica perfurados, para aumentar a área de contato ar-água.

$\mathrm{O}$ ar foi aquecido durante sua passagem pela primeira coluna, onde atinge cerca de $95 \%$ de umidade relativa. Esta coluna foi suprida constantemente com água esterilizada a uma vazão pré-determinada para manter o nível constante de água. $O$ ar passa então para a coluna seguinte onde é resfriado para a temperatura de fermentação de $33^{\circ} \mathrm{C}$ e a umidade atinge cerca de 99 a 100\%. Para prevenir o ressecamento do substrato durante a fermentação, devido à sua exposição às altas vazões de ar, foi mantido um fluxo de ar úmido. A vazão de ar úmido utilizada foi de $70 \mathrm{~L} / \mathrm{min}$. A temperatura do ar na coluna de fermentação foi controlada a $33^{\circ} \mathrm{C}$ através de um termo-regulador localizado na parte superior da coluna, conectado a uma fita de aquecimento de saturação. A coluna de fermentação, também de vidro, foi equipada com 4 pratos de Teflon, perfurados no fundo (aproximadamente $0,8 \mathrm{~cm}$ de diâmetro) para permitir uniformidade na distribuição do ar em toda a seção transversal da coluna. Sobre estes pratos, foi colocado um outro prato, também de Teflon, com perfuração mais fina $(0,16 \mathrm{~cm}$ de diâmetro), que suportou o substrato semi-sólido, evitando desta maneira, que escorresse para o fundo da coluna. $O$ ar efluente da coluna de fermentação foi então transferido para uma coluna coletora contendo $1500 \mathrm{~mL}$ de água, para captar materiais arrastados durante o processo fermentativo. Qualquer partícula sólida arrastada da coluna de fermentação, foi retida na câmara de controle de umidade e temneratura.

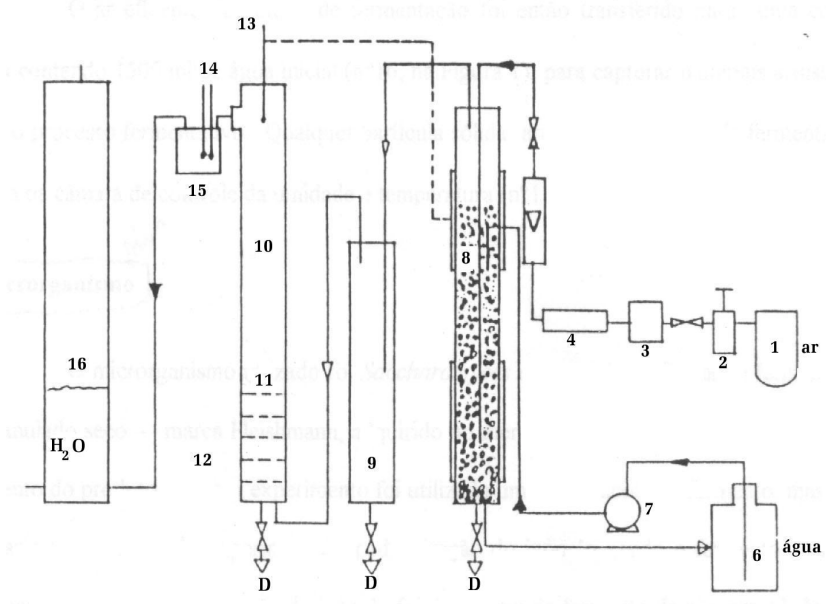

$\mathrm{D}=$ dreno

1. Entrada de ar; 2. Regulador de ar; 3. Aquecedor de ar; 4. Filtro de ar; 5 . Rotâmetro; 6 . Reservatório de água; 7 . Bomba peristáltica; 8 . Coluna de saturação; 9 . Coluna de resfriamento do ar; 10 . Coluna de fermentação; 11 . Prato de suporte; 12 . Pratos seco e úmido; 15 . Medidor de troca de umidade; 16 . Coluna coletora de água.

FIGURA 1. Diagrama do fermentador de leito fluidizado

\section{5 - Tratamento das Amostras para análise}

As amostras foram coletadas diretamente da coluna de fermentação, através de sua abertura superior. $A$ alíquota de $0,5 \mathrm{~g}$ foi diluída com $10 \mathrm{~mL}$ de água deionizada e $3 \mathrm{ml}$ desta solução foram diluídos em $3 \mathrm{ml}$ de água deionizada e determinada a concentração celular. $\mathrm{O}$ restante da amostra diluída (aproximadamente $7 \mathrm{~mL}$ ) foi centrifugado e o sobrenadante estocado em geladeira a $4^{\circ} \mathrm{C}$ para subseqüentes análises de proteínas. Foram ainda coletados no tempo zero e no final do período de incubação (após 24horas), uma alíquota de $5 \mathrm{~g}$ de substrato para análise do conteúdo de água.

\subsection{1 - Avaliação do crescimento celular}

Foi determinado por densidade óptica (Baush \& Lomb) a 595nm. Através da correlação gráfica (curva de calibração), convertendo as medidas de densidade óptica (absorbância) em concentração celular.

Para cada situação, com e sem cloreto de sódio $0,6 \mathrm{M}$, foi desenvolvida uma curva de calibração. A regressão linear Simples foi realizada através do Statgraphics- Statistical Graphics System, versão 5.0. Obtendo-se as seguintes equações:

1. meio contendo cloreto de sódio $0,6 \mathrm{M}: Y=-0,094+0,037 X \mathrm{r}^{2}=0,990$

2. meio sem cloreto de sódio: $\quad Y=0,039+0,022 X r^{2}=0,998$

2.5.2 - Cálculo da velocidade de crescimento e da velocidade específica de crescimento $(m)$

As velocidades de crescimento foram determinadas através da derivada da reta tangente ao ponto con- 
siderado, assumindo que há um arco de círculo $\mathrm{y}(\mathrm{x})$, passando por algum dos três pontos $A\left(x_{A}, y_{A}\right), B\left(x_{B}\right.$, $\left.y_{B}\right)$ e $C\left(x_{C}, y_{C}\right)$. A curva de referência para 0 cálculo destas derivadas, foi a curva de crescimento de Sacchoromyces cerevisiae, construída a partir das determinações da concentração média de biomassa obtida nos diferentes tempos de coleta (zero, um, três, cin$\mathrm{co}$, sete, nove, doze e vinte e quatro horas).

A Velocidade de crescimento, em mg/g.h, é expressa pela equação:

Velocidade de crescimento $=\mathrm{dx}, / \mathrm{dt}$

onde,

dx é a concentração celular $(\mathrm{mg} / \mathrm{g})$, e

dt corresponde ao tempo de crescimento (horas).

Velocidade específica de crescimento $(\mathrm{m})$, por hora $\left(h^{-1}\right)$, é expressa pela equação:

$m=1 / X_{-} \cdot d x / d t$

onde,

dx/dt é a velocidade de crescimento ( $\mathrm{mg} / \mathrm{g} . \mathrm{h})$ e

$X$ é a concentração celular $(\mathrm{mg} / \mathrm{g})$.

A produtividade $(P)$, em $\mathrm{mg} / \mathrm{g} . \mathrm{h}$, é expressa pela equação:

$P=X_{f}-X_{0} / t_{f}-t_{0}$

onde,

$\mathrm{Xf}=$ concentração celular final

Xo $=$ concentração celular inicial

$\mathrm{t}_{\mathrm{f}}=$ tempo final (hora)

$\mathrm{t}_{0}=$ tempo inicial (hora)

\subsection{3 - Análise do conteúdo de água}

Determinado conforme a AOAC [1].

\subsection{4 - Análise de proteínas extracelulares to- tais}

Determinadas pelo método de Bradford Coomassie Blue Dye Binding modificado por Bio-Rad Laboratory Microassay [4].

\subsection{5 - Análise Estatística}

A análise estatística, para verificar a diferença entre as médias das duas variáveis nos dois tratamentos (com $0.0 \mathrm{M}$ e $0,6 \mathrm{M}$ de $\mathrm{Nacl}$ ), foi realizada, utilizando-se a análise de variância com nível de significância de 0,05 .

\section{3.- RESULTADOS E DISCUSSÃO}

\section{1.- Produção de Biomassa}

A presença de cloreto de sódio $0,6 \mathrm{M}$ ao substrato, afeta diretamente a produção de biomassa, durante um período de 24 horas de fermentação (Figura 2).

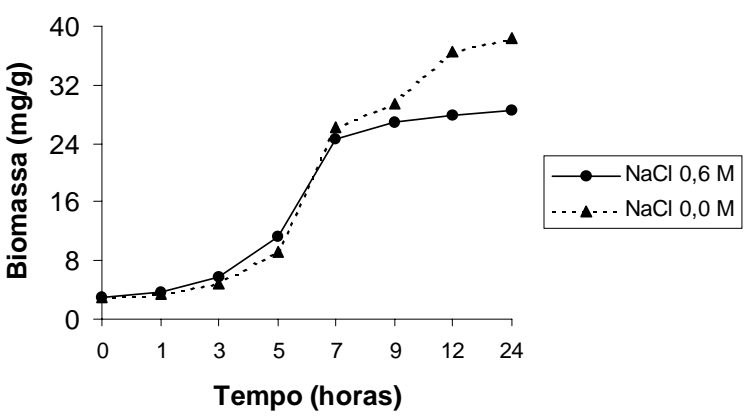

FIGURA 2. Produção de biomassa de Saccharomyces cerevisae, usando substrato semi-sólido em câmara fluidizada na presença e ausência de cloreto de sódio

Para os cultivos com adição de cloreto de sódio (Tabela 1), a média de produção de biomassa foi de $28,551 \mathrm{mg} / \mathrm{g}$ de substrato, correspondendo a um aumento de aproximadamente 10 vezes superior à concentração inicial (tempo zero). Nos cultivos sem adição de cloreto de sodio ( Tabela 2) a média foi de $38,443 \mathrm{mg} /$ $\mathrm{g}$ de substrato, representando um aumento de 13 vezes à concentração inicial de biomassa $(F=245,784$; $\mathrm{P}<0,05)$, ou seja, uma produção de biomassa da ordem de $25,73 \%$ superior quando comparada com o experimento adicionado de cloreto de sódio.

TABELA 1. Velocidade de crescimento ( $d x / d t)$ e velocidade específica de crescimento de Saccharomyces cerevisae, cultivada na presença de cloreto de sódio 0,6M em câmara fluidizada.

\begin{tabular}{ccc}
\hline $\begin{array}{r}\text { tempo } \\
\text { (horas) }\end{array}$ & $\begin{array}{c}\mathrm{d} \times / \mathrm{dt} \\
(\mathrm{mg} / \mathrm{g} \cdot \mathrm{h})\end{array}$ & $\begin{array}{c}\mu \\
\left(\mathrm{h}^{-1}\right)\end{array}$ \\
\hline 0 & - & - \\
1 & 0,908 & 0,243 \\
3 & 1,710 & 0,300 \\
5 & 3,796 & 0,339 \\
7 & 1,306 & 0,053 \\
9 & 0,376 & 0,014 \\
12 & 0,111 & 0,004 \\
24 & - & - \\
\hline
\end{tabular}

(-) Valores nulos ou negativos

Estes resultados podem ser comparados àqueles obtidos por WEI, TANNER, MALANEY [25] em cujos experimentos observaram o mesmo efeito, mas com uma produção $30-35 \%$ superior nos experimentos sem a presença de cloreto de sódio exógeno. 
TABELA 2. Velocidade de crescimento ( $d x / d t)$ e velocidade específica de crescimento de Saccharomyces cerevisae, cultivada na ausência de cloreto de sódio em câmara fluidizada.

\begin{tabular}{ccc}
\hline $\begin{array}{c}\text { tempo } \\
\text { (horas) }\end{array}$ & $\begin{array}{c}\mathrm{dx} / \mathrm{dt} \\
(\mathrm{mg} / \mathrm{g} \cdot \mathrm{h})\end{array}$ & $\begin{array}{c}\mu \\
\left(\mathrm{h}^{-1}\right)\end{array}$ \\
\hline 0 & - & - \\
1 & 0,908 & 0,243 \\
3 & 1,710 & 0,300 \\
5 & 3,796 & 0,339 \\
7 & 1,306 & 0,053 \\
9 & 0,376 & 0,014 \\
12 & 0,111 & 0,004 \\
24 & - & - \\
\hline
\end{tabular}

(-) Valores nulos ou negativos

Tanto na presença de cloreto de sódio, quanto na sua ausência, observa-se que a maior produção de biomassa ocorreu no período de 7 a 9 horas de fermentação. A fase de crescimento celular a partir daí, em ambos os experimentos, apesar de ser ascendente é quase estacionária, até o final do período, provavelmente como consequência do esgotamento de algum nutriente ou formação de metabólitos indesejáveis. Após este período pode-se observar uma diferença acentuada no nível de produção nos dois tratamentos.

Em termos de velocidade específica de crescimento, os maiores valores foram observados nos experimentos sem adição de cloreto de sódio (0,350/h), enquanto que com a adição de cloreto de sódio foi de $0,339 / h$. Estes resultados podem ser comparados com os obtidos por HONG [9] que obteve em condições semelhantes um crescimento específico de $0,40 / \mathrm{h}$. Como comparação, em uma cultura líquida, a velocidade específica de crescimento varia entre 0,2 e 0,25/h, desde que alguns parâmetros como concentração de açúcar, disponibilidade de oxigênio, principalmente, sejam adequadamente otimizados. O significativo incremento na velocidade específica de crescimento em nossos experimentos e no de outros autores [3,9], fazendo uso de câmaras fluidizadas podem ser atribuídos a uma meIhor eficiência da transferência de oxigênio como resultado de uma vigorosa agitação e aumento da superfície de contato proporcionadas pelo processo.

\section{2.- Produção de proteínas extracelulares}

Comparando-se a Figura 3, que apresenta a produção de proteínas extracelulares totais, com a Figura 2 (produção de biomassa), pode-se observar que a adição de cloreto de sódio $(0,6 \mathrm{M})$ promove um aumento na produção destas proteínas e diminui a produção de biomassa. Em ambos os tratamentos, a concentração máxima de proteínas extracelulares ocorre no final do período de fermentação (24 horas). A adição de cloreto de sódio $0,6 \mathrm{M}$ ao substrato provocou um incremento na produção de proteínas extracelulares totais da ordem de $36,86 \%$, considerando todo o período de fermentação. A concentração máxima destas proteínas foi de $14,660 \mathrm{mg} / \mathrm{g}$ de substrato no tratamento com adição de cloreto de sódio o que representa um incremento de 14 vezes em relação a concentração inicial. Por outro lado, no tratamento sem cloreto de sódio a máxima concentração foi de $9,256 \mathrm{mgg}$ de substrato, o que equivale a um aumento de 9 vezes a concentração inicial.

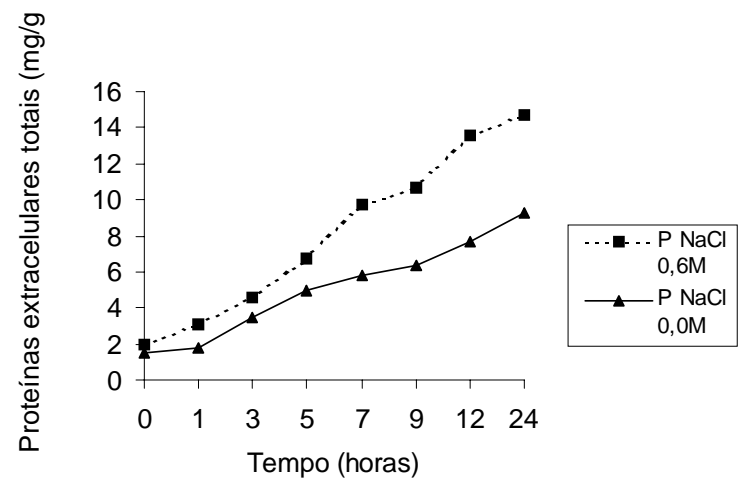

FIGURA 3. Produção de proteínas extracelulares totais por Saccharomyces cerevisae, usando substrato semi-sólido em câmara fluidizada na presença e ausência de cloreto de sódio.

Outros autores têm demonstrado que a produção de proteínas extracelulares totais, bem como a produção de lisina e outros aminoácidos tem atingido seu pico máximo de concentração em torno de 8 a 12 horas de fermentação $[2,11]$. Os dados obtidos no presente trabalho indicam, da mesma forma, que a produção destas proteínas atingiram o melhor desempenho durante o período de 9 a 12 horas. O aumento da concentração de cloreto de sódio no substrato obedece a uma ordem inversa ao crescimento celular até um limite de $1,2 \mathrm{M}$, onde o crescimento celular é zero [3]. O aumento da produção de proteínas extracelulares e aminoácidos (principalmente lisina) na presença de cloreto de sódio pode estar relacionado com a velocidade de consumo de glicose pelo microrganismo (Saccharomyces cerevisae). Tem-se observado que na presença deste sal a velocidade específica de consumo de glicose é reduzida quando comparada as mesmas condições, mas sem a presença do sal $[22,25]$. Por outro lado, aventase também a hipótese que pode ocorrer uma inibição parcial ou total das enzimas que degradam aminoácidos, principalmente a lisina $[12,22]$.

\section{4 - CONCLUSÕES}

O uso de câmaras fluidizadas para a produção de biomassa parece ser um avanço sobre as técnicas de fermentações em estado sólido convencionais, em função de suas inúmeras vantagens, especialmente sua alta produtividade na ausência de cloreto de sódio. A adição de cloreto de sódio $0,6 \mathrm{M}$ no processo fermentativo utilizado, induz a um aumento na produção de proteínas extracelulares totais. 


\section{5 - REFERÊNCIAS BIBLIOGRÁFICAS}

[1] OFICIAL METHODS OF ANALYSIS. 1984. Association of Oficial Analytical chemists (AOAC) 14 ed. Arlington: VA, $1141 \mathrm{p}$.

[2] BAKER, D.S. Overproduction of intracellular L-lysine and cellular protein in the alcohol-producing batch fermentation of baker's yeast. 1985. Tesis. Nashville (VU), Vanderbilt University.

[3] BAKER, D. S. et al. The effect of salts in fermenting mashes on the microbiological assay of L-lisine. Folia Microbiologica. v.31, p.187-195, 1986.

[4] BIO-RAD LABORATORIES - Chemical Division, 1984. BioRad protein assays. Hércules: (US/EG Bulletin, 1069).

[5] BRYLE, D. et al. Effect of feeding food yeast and nucleic acids metabolites on rat growth. In International Symposium on Food and Biotechnology. Proceedings of the International Symposium on Food and Biotechnology, Quebec, 1986.

[6] CAMPBELL, M.K. 1991. Biochemistry. Sainders College Publishing, p. 480-487.

[7] CHRISTIAN, J. H. B.; WALTHO, J. A. The composition of Staphylococcus aureus in relation to the water activity of the growth medium. Journal of Genetic Microbiology. v.35, p. 205-213, 1964.

[8] CRUEGER, W.; CRUEGER, A. 1990. Biotechnology - A textbook of industrial microbiology. 2 ed. Sunderland (MA), Sinauer Associates, $357 \mathrm{p}$.

[9] HONG, K. Semi-solid state fermentation of baker's yeast in an air-fluidized bed fermentor. 198p. Tesis. Vanderbilt University.

[10] LIMA, U. A.; AQUARONE, E.; BORZANI, W. 1975. Biotecnologia - Tecnologia das fermentações. Edgar Blucher, $285 \mathrm{p}$.

[11] MALANEY, G. W.; TANNER, R. D. The effect of sodium cloride on the urea cycle amino acids within baker's yeast (Saccharomyces cerevisae) during aereted fermentation of glucose. Biotechnology and Applied Biochemistry. Duluth (MN), v.10, p.42-28, 1988.

[12] MALANEY, G. W.; TANNER, R. D.; RODRIGUES, A. M. Production of extracellular and intracellular free amino acids during aereted fermentation of glucose baker's yeast (Saccharomyces cerevisae). Folia Microbiologica. London,, v.36, n.5, p.468-477, 1991.

[13] MARTINES-FORCE, E.; BENITEZ, T. Changes in yeast amino acids pool with respiratory versus fermentative metabolism.
Biotechnology and Bioengineering. New York, v.40, p. 643-649, 1992.

[14] MAXON, M. D.; JOHNSON, M. J. Association studies on propagation of baker's yeast. Industrial and Engineering Chemistry. Washinton (DC), v.45,n.11, p.2554-2560, 1953.

[15] MISHIRA, I. M.; EL-TEMTAMY, S. A.; SCHUGERL, K. [s.t.] European Journal of Applied Microbiology and Biotechnology. Berlim, v.16, p.197-302, 1982.

[16] NORKRANS, B. Studies on marine-occuring yeast: growth related to $\mathrm{pH}, \mathrm{NaCl}$ concentration and temperature. Archeological Mikrobiology, v.54, p. 374-392, 1966.

[17] REED, G. Use of microbial cultures: yeast products. Food Technology. v.35, n.1, p.89-94, 1981.

[18] REED, G.; NAGODAWITHANA, T.W. 1991. Yeast Technology. 2 ed. Avi, New York, 454 p.

[19] RICHMOND, L.D. The effect of salt concentration on the intracellular free lysine content of growing baker's yeast. 1980, 103 p. Tesis. Nashville: VU, Vanderbilt University.

[20] SCHRIMSHAW, N.S. Nutricional and tolerance considerations in the feedings of single cell protein. In International Symposium on Food and Biotechnology, Proceedings of the International Symposium on Food and Biotechnology. Quebec, 1986.

[21] TAJIMA, K.; YOSHIZUMI, H.; TERASHIMA, Y. Salt and sugar tolerances of yeast on alcoholic fermentation. I. The inhibition of fermentation by the highly concentrated salts in molasses. Journal of Fermentation Technology. Osaka, v.44, p. 77-84, 1966.

[22] TANNER, R.D.; MALANEY, G.W.; DANZO, B.J. Protein entrainment during baker's yeast fermentation on semisolid substrate in a air-fluidized bed fermentor. Bioprocess Engineering. New York, v.4, p.209-215. 1989.

[23] TEMPEST, D.W.; MEERS, J.L.; BROWN, C.M. Influence of environment on the free amino acid pool. Journal of Genetic Microbiology. v.64, p.171-185, 1970.

[24] UMEMOTO, S.; IRIE, Y.; IMAI, T. The effect of electrolytes concentration on alcoholic fermentation of molasses. I. Glycerol accumulation in the medium caused by high concentrations of electrolytes. Journal of Fermentation Technology. Osaka, v.45, p.117-124, 1967.

[25] WEI, C.J.; TANNER, R.D. ; MALANEY, G.W. Effect of sodium cloride on baker's yeast growing in gelatin. Applied Environmental Microbiology. Washington, v.43, n.4, p.757-767, 1982. 